\title{
Two Case Studies Using Mock-Ups for Planning Adult and Neonatal Intensive Care Facilities
}

\author{
Sue Hignett ${ }^{1, *}$, Jun Lu², Mike Fray ${ }^{1}$ \\ ${ }^{1}$ Department of Ergonomics, Loughborough University, Loughborough, \\ Leicestershire, $U K$ \\ ${ }^{2}$ Department of Civil and Building Engineering, Loughborough University, \\ Loughborough, Leicestershire, UK
}

\begin{abstract}
This paper describes two case studies using a 5-step protocol to determine functional space requirements for cardiac and neonatal intensive care clinical activities. Functional space experiments were conducted to determine the spatial requirements (defined as the minimumsized rectangle to encompass the Link Analysis). The data were collected with multi-directional filming and analysed frame-by-frame to plot the movements between the nurses and other components in the space. The average clinical functional space for the adult critical care unit was $22.83 \mathrm{~m}^{2}$ (excluding family and hygiene space and in-room storage). The average functional clinical space for neonatal intensive care unit was $13.5 \mathrm{~m}^{2}$ (excluding circulation and storage). The use of the 5-step protocol is reviewed, with limitations in case study 1 addressed in case study 2 . The findings from both case studies have been incorporated into government guidance and achieved knowledge transfer by being implemented in building design.
\end{abstract}

Keywords: hospital design and construction, architecture, space simulation, human engineering

\section{INTRODUCTION}

Spatial dimensions for clinical tasks have been recommended for many years but very little empirical evidence has offered to support recommendations [1]. Many authors have commented that staff and patient safety can be compromised if insufficient space is provided [2-6]. Even if sufficient space is available, the layout and ergonomic design of workspace may restrict activities and contribute to adverse events [7-8]. The physical environment and equipment have been identified as two of the seven main types of performance obstacles experienced by Intensive Care Unit (ICU) nurses [9] and it has been suggested that hospitals are not designed with the explicit goal of enhancing safety through facility design [10].

*Corresponding author: Sue Hignett. UK. Tel: +44 (0)1509 223003, Fax: +44 (0)1509 223940

E-mail: S.M.Hignett@lboro.ac.uk 
There is a growing trend in the design community for evidence-based design (EBD) that mirrors evidence-based medicine [11]. Hamilton [12] describes this as 'design based on research and analysis of what has come before rather than ... subjective decisions being made about what's right in the facilities'. The importance of clinical staff participating in healthcare building design has been emphasised by a number of authors [8, 13-16]. The systematic use of mock-ups (including user-needs analysis and task analysis) as part of the design process has been encouraged as part of a closer relationship between Ergonomics and Architecture [17]. The use of mock-ups, as part of a participatory design process, is recommended by a number of authors to enable staff to experience all aspects of the design including getting the feel of the space, evaluating various aspects and providing feedback [13, 15, 18-21]. Patterson and Abrahão [22] describe this relationship as 'through Ergonomics it is possible to understand human activities and their design requirements. Through Architecture it is possible to provide the elements to make them happen'. Watkins et al. [23] report that the EBD literature lacks examples of mock-ups as part of systematic, applied multiple or mixed methods research. They conclude that not enough architectural programming [24] efforts use mock-ups to evaluate the usefulness of EBD solutions and strategies or take advantage of the combination of participatory, quantitative and qualitative techniques afforded by mock-ups.

The design of an ICU needs to both facilitate the provision of care and provide a low stress environment for the patients and their families or significant others [25, 26]. The first adult ICUs were built in the early to mid 1950s, with open wards; second and third generation ICUs (1970s and 1980s) had individual rooms, moving from walled cubicles to folding/sliding doors with increased level of control. It is predicted that the future ICUs will have individual rooms with increased privacy [27], possibly with adaptable acuity [28-30].

Neonatal Intensive Care Units (NICUs) vary in design but are often one large, open room with the cots (incubators) arranged side by side. This has observation and access advantages but also has disadvantages, for example, in noise levels, lighting, and privacy [31-33]. Recently, there have been moves toward more family-centred care, accompanied by a trend to increase the number of single rooms [34]. In 2007-08 the Department of Health (DH) in the United Kingdom (UK) carried out a review of national design guidance for Neonatal Units [35]. As part of the review, the authors were asked to determine the space required to care for and to treat neonates using empirical principles [36, 37].

This paper describes the use of a 5-step protocol to determine functional space requirements for clinical activities (care and treatment) in Cardiac Intensive Care Units (CICUs) and NICUs. The functional space is defined as a task ergonomic envelope [38] 'the incompressible spatial requirements for functional activities (dimensions with aspect ratio). It provides a complex spatial representation to incorporate multiple activities, participants and interfaces' [39]. The case studies were carried out as part of two different projects. The first focussed on the collection of empirical data as part of the development of the protocol, and the second was part of a knowledge transfer project. The further development of the protocol is reviewed, with limitations in case study 1 addressed in case study 2 . 


\section{METHOD}

Both case studies use a 5-step protocol developed by Hignett et al. [39] to support decision-making for clinical space planning (for patient interactions) in healthcare facilities (Figure 1). This type of space testing was originally used in 1955 [40] and has been used to recommend minimum patient handling space requirements in bed spaces [41] and shower/toilet rooms [42].

1. Define an example to test or build to produce a layout from 'real life'. This can typically use data from professional guidelines and/or examples of current facilities with a range of different layouts.

2. Observe task activities using Hierarchical Task Analysis (HTA) and Link Analysis (LA) to develop a test scenario based on the frequency and criticality of activities.

- HTA divides a task into sub-tasks until a stopping point is reached when the task cannot be further described.

- LA uses observational data about the links between components in a system. The links are recorded in link tables and spatial diagrams. The space requirement is defined as the minimum-sized rectangle to encompass all the task movements documented by the link analysis.

3. Conduct Functional Space Experiments (FSEs) with the test scenario to determine the average spatial requirements.

4. Take additional information into account, for example, storage, family space and circulation, regulations, standards, etc.

5. Use steps 1-4 to review and test spatial requirements following changes in working practices and the introduction of new equipment/technology

Figure 1. 5 steps for clinical spatial planning [39].

Link Analysis (LA) is a technique for analysing movements between individuals and components in a system using observable or measurable data to record and represent the nature and frequency of the links. It is used to identify problems in the layout of a working area. A link will occur when an individual shifts attention or physically moves from one part of the system to another [43]. LA has limitations in terms of what can be analysed; for example, it can only record spatial relationships.

HTA is a technique to analyse data by breaking a task down into sub-tasks until a stopping point is reached when the task cannot be further broken or described [44]. HTA was used to re-describe the observational data to arrive at a detailed understanding of clinical activities in the development of the test scenarios.

\section{Participants}

Both case studies were carried out at a large UK teaching hospital with over 11,500 staff on three sites. Clinical staff in the CICU and NICU were invited to participate in the project. Patients on the CICU were approached on the day before their operation and 
Table 1. Participants from the CICU, NICU and Expert Review Group

\begin{tabular}{lcc}
\hline Step & CICU & NICU \\
\hline Observation & Nurses $(n=28)$ & Clinical staff $(n=28)$ \\
& Patients $(n=25)$ & Neonates $(n=15)$ \\
FSEs & Nurses $(n=18)$ & Clinical staff $(n=21)$ \\
Expert review & & National expert panel $(n=6)$
\end{tabular}

the parents of the neonates were approached, under the guidance of the nursing staff, on the first day of the observation period. All participants were given an information sheet and had an opportunity to discuss the project with the researcher (Table 1).

A national expert panel reviewed the NICU results (case study 2) with respect to the spatial recommendation. The panel included senior neonatal medical $(n=3)$ and nursing $(n=3)$ staff from five UK hospitals and the Department of Health Advisory Panel.

\section{Case study 1: Adult CICU}

The tasks were determined by a previous field study, which used example layouts from four UK hospitals built or refurbished since 2001 [39]. Observations were carried out over five days (on morning, afternoon and evening shifts). Data were recorded by field notes and sketches to record the purpose, duration, location, and participants for a wide variety of tasks (Table 2).

These data were reviewed with clinical nurse advisors to develop the following three task scenarios that incorporated the most frequent and space critical activities (see example in Figure 2 for task 1):

1. Washing and dressing a patient and moving them from the bed to wheelchair using a lifter (bed wash/lifter task) with 2-3 nurses.

2. Transferring a patient from bed to another bed (bed-to-bed task) with 2-3 nurses. 3. Resuscitating a patient (resuscitation task) with 4-6 nurses.

Three sessions were run with 18 participating nurses. Each session had two groups of nurses ( $n=3$ per group), giving a total of six groups testing the four layouts by repeatedly performing the three tasks. Expert clinical advisors in moving and handling recommended that a minimum of three nurses should be involved in the bed-to-bed transfer, so tasks (1) and (2) were carried out with groups of three nurses. The resuscitation task was carried out with two groups ( $\mathrm{n}=6$ per group) to simulate the number of staff who may be involved in this activity, with additional clinicians from the resuscitation team joining the ward staff.

The FSEs were simulated in a full-size laboratory mock-up (Figure 3). Coloured tapes were used to mark the boundaries of the template with additional calibration lines at $0.2 \mathrm{~m}$ intervals to record and measure the exact space required. The mock-up used a module rail (gantry) rather than a headwall service system. A full-size $17 \mathrm{~kg}$ articulated mannequin was used as the patient to achieve spatial occupancy without introducing 
Table 2. Observations in CICU to develop scenario of FSEs

\begin{tabular}{|c|c|c|c|c|}
\hline Tasks observed & $\begin{array}{l}\text { No. of times } \\
\text { tasks observed }\end{array}$ & $\begin{array}{l}\text { Duration } \\
\text { (mins) }\end{array}$ & $\begin{array}{l}\text { No. of nurses } \\
\text { involved }\end{array}$ & $\begin{array}{l}\text { Patient } \\
\text { condition }\end{array}$ \\
\hline $\begin{array}{l}\text { Washing, shaving a patient, } \\
\text { changing bed sheets }\end{array}$ & 1 & 40 & $2-3$ & $\begin{array}{l}\text { Awake, } \\
\text { dependent }\end{array}$ \\
\hline $\begin{array}{l}\text { Washing a patient, } \\
\text { changing bed sheets }\end{array}$ & 14 & $30-40$ & $2-3$ & $\begin{array}{c}\text { Asleep/awake, } \\
\text { dependent }\end{array}$ \\
\hline $\begin{array}{l}\text { Checking a patient's } \\
\text { rectum/anus }\end{array}$ & 1 & $5-10$ & $1-2$ & Asleep \\
\hline $\begin{array}{l}\text { Repositioning (moving/sliding) } \\
\text { a patient on the bed }\end{array}$ & 5 & 5 & $2-3$ & $\begin{array}{c}\text { Asleep/awake, } \\
\text { dependent }\end{array}$ \\
\hline $\begin{array}{l}\text { Washing, dressing, and moving } \\
\text { a patient from bed to chair } \\
\text { or wheelchair without a hoist }\end{array}$ & 3 & $20-40$ & $2-3$ & $\begin{array}{l}\text { Awake, less } \\
\text { dependent }\end{array}$ \\
\hline $\begin{array}{l}\text { Dressing and moving a patient } \\
\text { from bed to chair or } \\
\text { wheelchair without a hoist }\end{array}$ & 4 & $20-30$ & $2-3$ & $\begin{array}{l}\text { Awake, less } \\
\text { dependent }\end{array}$ \\
\hline $\begin{array}{l}\text { Moving a patient from chair } \\
\text { to wheelchair }\end{array}$ & 1 & 5 & $1-2$ & $\begin{array}{l}\text { Awake, less } \\
\text { dependent }\end{array}$ \\
\hline $\begin{array}{l}\text { Transferring a patient from } \\
\text { bed to bed }\end{array}$ & 1 & 10 & $2-3$ & $\begin{array}{l}\text { Awake, } \\
\text { dependent }\end{array}$ \\
\hline $\begin{array}{l}\text { Front chest } \mathrm{X} \text {-ray with mobile } \\
\mathrm{X} \text {-ray machine }\end{array}$ & 1 & $10-15$ & $2-3$ & $\begin{array}{c}\text { Asleep/awake, } \\
\text { dependent }\end{array}$ \\
\hline
\end{tabular}

Female patient 82 years old, Clostridium difficile infection, admitted with urine infections and falls, asking for toilet a lot, starts having diarrhoea, specimen sent off.

Very large bowel movement, incontinent of faeces in the bed and the only sensible way to manage hygiene needs is to bathe.

Start point - patient in the bed to be washed

End point - outside room on lifter

Equipment to be used: patient bed, over bed table, locker, patient chair, bin, wash basin (in some single rooms), visitor chair (in single rooms), dressing trolley (extra gloves and aprons outside the bed space), lifter/sling, drip stand (PAC), commode chair (in single rooms), patient property bag, bowl, walking frame

Figure 2. Scenario for washing and dressing a patient and moving the patient from the bed to wheelchair using a lifter (bed wash/lifter task).

manual handling risks. The multi-directional video data (from 4 cameras) were analysed frame by frame using LA. The movement of each nurse was plotted individually and then overlaid with that of their colleagues for each task and template to give 48 data sets of composite LAs (see example for resuscitation in Figure 4). 


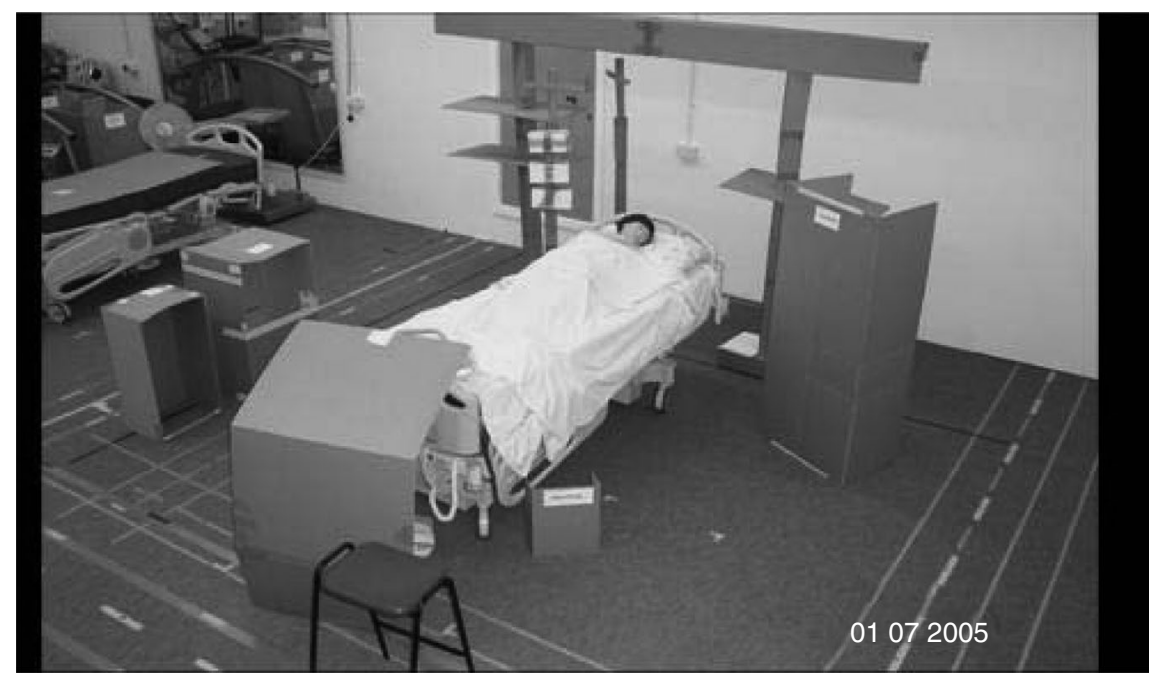

Figure 3. CICU mock-up.

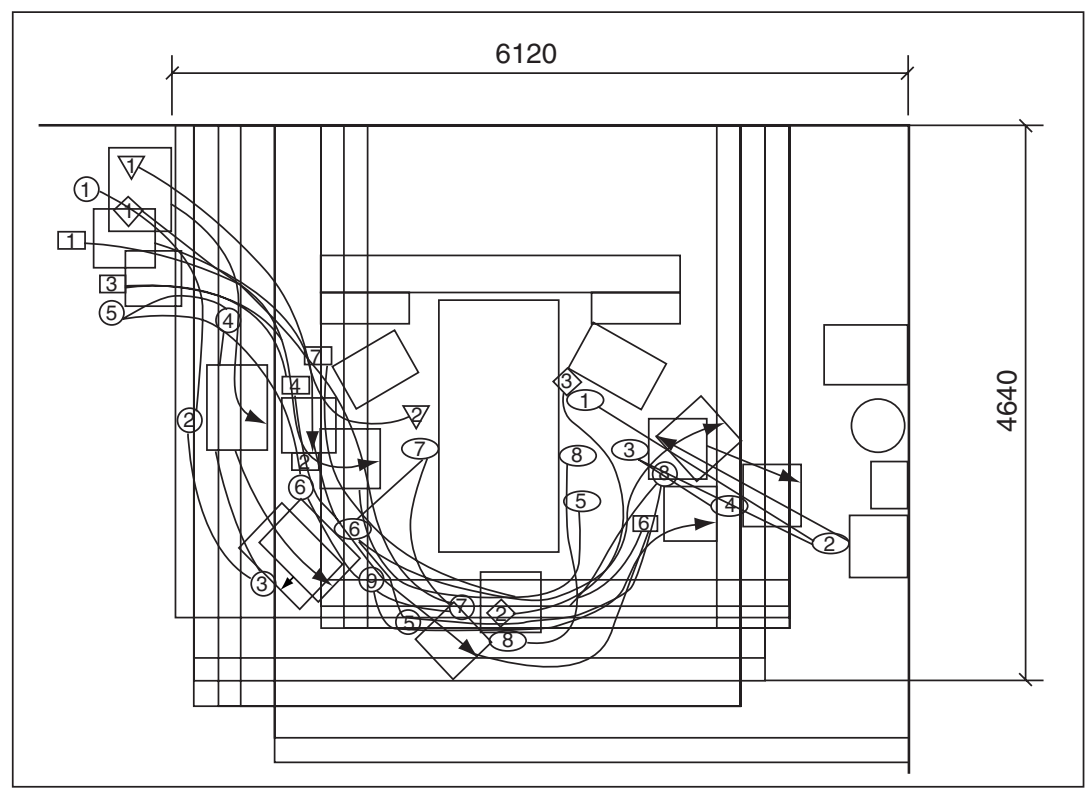

Figure 4. Composite LA for resuscitation task in CICU (template dimensions: $6,120 \mathrm{~mm} \times 4,640 \mathrm{~mm})$. Each symbol represents one nurse with numbered sequential positions. The arrowed lines represent the movement of equipment. 


\section{Case study 2: Neonatal Intensive Care Unit}

Senior nursing staff advised the research team that there was minimal difference between day and night clinical activities (apart from the morning ward round), so observational data were collected between 0900 and 1700 for 9 days ( 87 observations for 28 clinical tasks, Table 3) until no new data were generated.

These data were used to develop the NICU task scenario (Table 4).

Six FSEs were carried out by 21 clinical staff (some staff participated in more than one FSE). The scenario for the FSE was run as a continuous sequence of tasks (Table 4).

Table 3. Observations in NICU to develop scenario of FSEs

\begin{tabular}{|c|c|c|c|}
\hline & Task & $\begin{array}{l}\text { Duration } \\
\text { (minutes) }\end{array}$ & $\begin{array}{l}\text { No. of staff } \\
\text { involved }\end{array}$ \\
\hline 1 & Aspiration & 5 & 1 \\
\hline 2 & Tube feeding & $5-20$ & 1 \\
\hline 3 & Drug infusion & $5-10$ & 2 \\
\hline 4 & Changing IV fluid & 10 & 2 \\
\hline 5 & Physiotherapy & $10-15$ & 1 \\
\hline 6 & Suction & 10 & $1-2$ \\
\hline 7 & Mouth care & $5-10$ & 1 \\
\hline 8 & Wash/nappy change & $10-20$ & $1-2$ \\
\hline 9 & Repositioning/turning a baby & 5 & 1 \\
\hline 10 & Bed sheet change & $10-15$ & $1-2$ \\
\hline 11 & Collecting urine sample & 5 & $1-2$ \\
\hline 12 & Collecting the blood sample & $5-10$ & 1 \\
\hline 13 & X-Ray investigation & $10-15$ & 2 \\
\hline 14 & ECG investigation & 15 & 1 \\
\hline 15 & EEG investigation & $?$ & 2 \\
\hline 16 & Eye check & 20 & 2 \\
\hline 17 & Ultrasound investigation & $10-20$ & 1 \\
\hline 18 & Lumbar puncture & $15-30$ & 3 \\
\hline 19 & Blood testing & 10 & 1 \\
\hline 20 & Transferring a baby from incubator to cot & $10-15$ & 1 \\
\hline 21 & $\begin{array}{l}\text { Transferring a baby from incubator to and } \\
\text { from transport system }\end{array}$ & $10-15$ & $1-2$ \\
\hline 22 & Transferring a baby to special care & 10 & 2 \\
\hline 23 & Damp dusting & $10-20$ & 1 \\
\hline 24 & Extubation & 10 & 2 \\
\hline 25 & Taking the monitor off & 5 & 1 \\
\hline 26 & Taking the cord clamp off & 5 & 1 \\
\hline 27 & Getting a baby out of the cot/incubator & $10-20$ & 2 \\
\hline 28 & Body temperature check & 3 & 1 \\
\hline
\end{tabular}


Table 4. NICU task scenario

Tasks

1. Entering the unit by transport system

2. Transferring a baby from transport system to incubator

3. Putting the ventilator on

4. Connecting the monitor

5. Weighing a baby

6. Insertion of gastric tubes

7. Insertion of lines

8. Giving drugs and setting up fluids

9. Chest X-Ray check

(Baby deteriorated)

10. Resuscitation

11. Re-intubation

12. Putting the Nitric Oxide on

13. Giving new drugs and new fluids

14. Mother visiting on a hospital bed

\section{Participants}

$\mathrm{D} 1+\mathrm{N} 1$

$\mathrm{N} 1+\mathrm{N} 2$

$\mathrm{N} 1+\mathrm{D} 1$

N1

N1

N1

$\mathrm{D} 1+\mathrm{N} 1$.

$$
\mathrm{N} 1+\mathrm{N} 2
$$

N1

$\mathrm{D} 1+\mathrm{D} 2+\mathrm{N} 1$

$\mathrm{D} 1+\mathrm{N} 1$

$\mathrm{D} 1+\mathrm{D} 2$

$\mathrm{N} 1+\mathrm{N} 2$

(D1 writing report)

$$
\mathrm{N} 2+\mathrm{N} 3
$$

(N1 caring for baby)
Equipment /furniture

Incubator

Transport system

Ventilator

Monitor

Drip stand

Admission trolley

Armchair

Nurse chart desk

Nurse chair

Dressing trolley

X-Ray machine

Crash trolley

Nitric Oxide machine

Hospital bed

- Participants: Nurses: N1 (leading), N2, N3; Doctors: D1 (leading), D2.

- Mannequin: 25 weeks gestation (size).

- Start point: transport system in the corridor of the NICU.

- End point: mother's bed in the cot space.

Staff joined and left the FSE as indicated by the numbers of participants (doctors and nurses) for each task, with the leading doctor (D1) and leading nurse (N1) in attendance throughout the FSE. The FSE layout dimensions were taken from national guidelines [35] and two current examples. A mock-up was built for the FSE in the NICU using equipment and furniture from the NICU and a mannequin baby. Multi-directional video filming was used to record the movements of the participants, equipment, and furniture. Calibration lines were marked at $0.2 \mathrm{~m}$ intervals from the boundary to aid analysis. The data were analysed frame by frame to plot the movements of the participants, equipment, and furniture, and then combined into composite LAs (Figure 5) for the entire scenario, rather than individual tasks. 


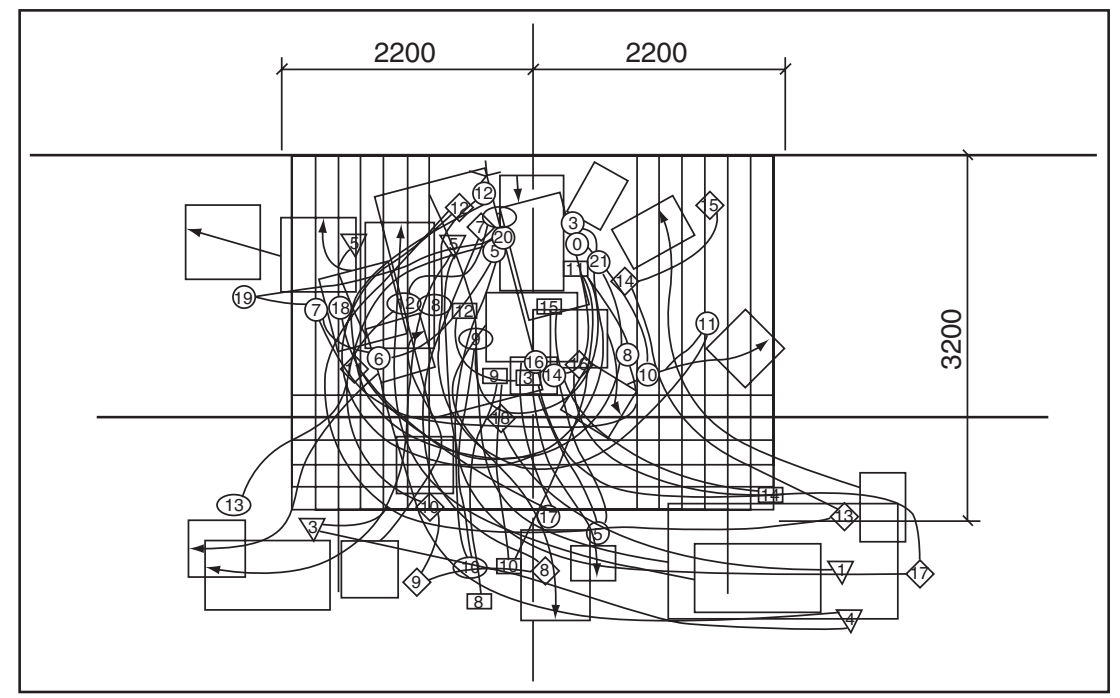

Figure 5. Composite LA for NICU (template dimensions: 4,400 $\mathrm{mm} \times 3,200 \mathrm{~mm}$ ). Each symbol represents one nurse with numbered sequential positions. The arrowed lines represent the movement of equipment.

Two additional FSEs were carried out by the six members of the expert panel using the same scenario in a full-size mock-up (floor area of $4.13 \mathrm{~m} \times 3.27 \mathrm{~m}$ marked with $0.1 \mathrm{~m}$ calibration lines) in an NICU at a London teaching hospital to enable them to experience the test scenario. Data were recorded with video, field notes, and work books. The workbooks were used to record individual comments and were completed after the FSEs during a review of their experience of the task scenario in a group discussion. Five completed work books were collected and analysed. The data from the FSEs and workbooks were compared to identify the key points for discussion about the task scenario.

\section{Ethics}

Ethical approval for this study was granted by Loughborough University and the National Health Service (MREC 04/MRE09/31[CICU], LREC 07\Q2501\111[NICU]). Research governance was granted by the participating NHS Trusts and honorary contracts were issued to the researchers.

\section{RESULTS}

\section{Case study 1}

The space occupied was measured for each trial and an average calculated for each task (Table 5). The bed-to-bed transfer task occupied most space with an average area of $23.26 \mathrm{~m}^{2}$ followed by the resuscitation task $\left(22.87 \mathrm{~m}^{2}\right)$ and the bed wash/lifter task $\left(22.36 \mathrm{~m}^{2}\right)$. The average spatial requirements from all the FSEs was $22.83 \mathrm{~m}^{2}$ (average 
Table 5. Case Study 1: CICU FSE results

\begin{tabular}{lccc}
\hline Task (No. of FSEs) & $\begin{array}{c}\text { Width }(\mathbf{m}) \\
\text { Average [SD] }\end{array}$ & $\begin{array}{c}\text { Length }(\mathbf{m}) \\
\text { Average [SD] }\end{array}$ & $\begin{array}{c}\text { Area }\left(\mathbf{m}^{\mathbf{2}}\right) \\
\text { Average [SD] }\end{array}$ \\
\hline Bed Wash $(\mathrm{n}=24)$ & $4.81[0.72]$ & $4.65[0.31]$ & $22.36[2.89]$ \\
Bed-to-bed transfer $(\mathrm{n}=24)$ & $4.87[0.80]$ & $4.80[0.36]$ & $23.26[3.13]$ \\
Resuscitation $(\mathrm{n}=12)$ & $4.89[0.68]$ & $4.67[0.33]$ & $22.87[3.91]$ \\
Average [SD] & $4.86[0.04]$ & $4.71[0.08]$ & $22.83[0.45]$
\end{tabular}

width of $4.86 \mathrm{~m}$, length of $4.71 \mathrm{~m}$ ). This is similar to the recommendation from Hendrich et al. [28] for a room area of $22.5 \mathrm{~m}^{2}$ (with an additional $13.5 \mathrm{~m}^{2}$ for family space, total $36 \mathrm{~m}^{2}$ ) and within the current UK recommendation of $26 \mathrm{~m}^{2}$. Hygiene space (en-suite toilet/shower facilities) have been considered elsewhere [38, 41]. Storage requirements should be determined at a local level as logistics and facilities management systems will vary; for example, just-in-time systems may require very little storage.

The limitations of this case study were, for the most part, due to the scope of the project. The funding did not support step 5 of the protocol. The project concluded at step 4, with recommendations for average spatial requirements and reference to additional information about storage, family space and hygiene. Figure 3 shows that much of the equipment in the FSE was constructed from cardboard. Although this achieved the requirement of space occupancy, it is likely that this may have contributed to the limitations.

\section{Case study 2}

The area for the NICU functional clinical space ranged from a minimum of $12.4 \mathrm{~m}^{2}$ to a maximum of $14.85 \mathrm{~m}^{2}$, with an average of $13.5 \mathrm{~m}^{2}$ (Table 6). Step 4 of the protocol recommends that additional information for storage and circulation should be included. It is suggested that an additional $0.6 \mathrm{~m}$ could be added for circulation based on the recommendation from the $7^{\text {th }}$ Consensus US Committee ${ }^{45}$ that "there shall be an aisle adjacent to each infant space with a minimum width of 4 feet $(1.2 \mathrm{~m})$ in multiple bed

Table 6. Case Study 2: NICU FSE results

\begin{tabular}{lccc}
\hline Session & Width $(\mathbf{m})$ & Length $(\mathbf{m})$ & Area $\left(\mathbf{m}^{\mathbf{2}}\right)$ \\
\hline 1 & 4.5 & 3.3 & 14.85 \\
2 & 3.8 & 3.5 & 13.3 \\
3 & 4.4 & 3.2 & 14.08 \\
4 & 4.2 & 3.2 & 13.44 \\
5 & 3.9 & 3.3 & 12.87 \\
6 & 4.0 & 3.1 & 12.4 \\
Average [SD] & $4.13[0.28]$ & $3.27[0.14]$ & $13.5[0.87]$
\end{tabular}


rooms". Storage can be estimated as a standard cabinet width of $0.6 \mathrm{~m}$. This would increase the cot space to $18.46 \mathrm{~m}^{2}$ [4.13 $\left.\mathrm{m} \times(3.27 \mathrm{~m}+0.6 \mathrm{~m}+0.6 \mathrm{~m})\right]$, similar to the recommendation from Mathur [46] of $18.58 \mathrm{~m}^{2}$. No recommendations or previous research were found for family space requirements in NICU accommodation.

For this study, it was possible to review the findings (step 5) with an expert panel. It was agreed that the average space recommendation would accommodate variance in working practices. The key points identified for discussion were staff numbers, equipment requirements, bed head services (gantry, pendant and booms), sterile activities and infection control including preparation, disposal and wash hand basins for the separation of clean and dirty tasks, and mother-baby interactions. They concluded that preparing drugs with aseptic and aseptic non-touch techniques was a space critical task and should have a separate ward dispensing area to minimise the risk of error. Sharps boxes should be in the individual cot space, but wash hand basins (or ward troughs) and attendant waste bins could be outside the clinical treatment/care space for multi-occupancy accommodation in one large open room.

One of the most space critical tasks was a mother visiting her baby on a bed (task 14). The frequency of this task will depend on the layout of the hospital (obstetric ward adjacency to NICU). It was important to include this task to support future advances in neonatal science.

\section{DISCUSSION}

The two case studies used the same 5-step protocol, with case study 1 using steps 1-4 and case study 2 using steps $1-5$, to evaluate the space requirements for adult and critical care units. The NICU case study addressed some of the limitations of the CICU study; for example, step 5 (review) was completed and the equipment used in the FSE was borrowed from the NICU rather than constructed from cardboard. We found in case study 1 that it was harder for the participating nurses to perform the tasks with simulated equipment than in case study 2 using real equipment. Mobile lightweight screens were used for all FSEs to address the lack of walls/curtains. These provided a physical boundary to remind staff to either work within the available space or to make a decision to increase the space by moving the screen.

A limitation of both case studies was the lack of evaluation for the design of the provision of services (electrical, vacuum, air and oxygen). In Adult ICUs, there are two principal systems for the delivery of these services, a modular rail (horizontal) or power column (vertical) [47-48]. A rail system having the intravenous lines, tubes, etc. fanning out from the patient, is adjustable for individual patients. There is access for right and left-handed caregivers, and the floor space is free with everything hanging from the rail (minimal tangling) $[8,18]$. The power column (vertical pendant) has the lines, tubes, etc. leaving the patient and converging in one area. This can facilitate $360^{\circ}$ access to the patient and increase efficiency with controls at fingertips and equipment congregated in one area, but the lines can get tangled [18, 26, 49]. This limitation was addressed in the NICU case study with the inclusion of different bed head systems for the FSEs (wall mounted) and expert panel review (pendant system). It was felt that the 
column design could offer an acceptable compromise with less adjustability but the services located in a smaller footprint.

The spatial recommendations are based on the average spatial dimensions for direct patient care activities. We have had many discussions at national and international forums with architects, healthcare planners, clinicians and ergonomists. An ergonomic perspective, based on anthropometry, would recommend designing based on the minimal acceptable dimension, for example, $95^{\text {th }}$ percentile to accommodate all but $5 \%$ of the population [50]. However, the complexity of these working environments and real world financial constraints have resulted in a pragmatic compromise. This approach was confirmed in case study 2, which was part of a knowledge transfer project (where research is translated into practice), in the expert panel review. It is possible that there may be non-patient care activities that require additional space (e.g. charting and interactions with co-workers).

The findings from the case study 2 have been incorporated in a national guidance [51] and is being used as part of a $£ 9$ million redevelopment of the neonatal facilities at the participating hospital [52].

\section{CONCLUSION}

The provision of functional space in a critical care environment is recognised to be important for both patient and staff safety. This research provides empirical data to support a spatial requirement of $22.83 \mathrm{~m}^{2}$ (width $4.86 \mathrm{~m} \times$ length $4.71 \mathrm{~m}$ ) as the average task space in CICU based on the average length (bed-to-bed transfer) and width (resuscitation) dimensions. The recommended dimensions for the NICU functional clinical space of $13.50 \mathrm{~m}^{2}$ (width $4.13 \mathrm{~m} \times$ length $3.27 \mathrm{~m}$ ) were reviewed and validated by an expert group. The test scenario was validated with a minor adjustment (inclusion of an oscillator). The complexity of the spatial requirements suggests that circulation and storage considerations must be included. The space requirements recommendations for both case studies are based on an single space requirement, so care needs to be taken when extrapolating this to multiple occupancy bed/bay areas to maintain the minimum space requirement. The method of link analysis was found to be very effective for plotting the movements of the clinical staff and accounting for the complexity of the tasks. This method, in combination with observational field studies, provides a simple but effective way of determining the functional space requirements for clinical activities.

\section{ACKNOWLEDGEMENTS}

We would like to thank staff, patients, parents and babies on the Cardiac and Neonatal Intensive Care Units of University Hospitals of Leicester NHS Trust for participating in this research. We are also grateful to the national expert group for their input and support.

This work was supported by Grants no: B(02)13, B(05)02 and COI/5768 from the Department of Health Estates and Facilities Management Directorate (UK). This paper presents independent research commissioned by the National Institute for Health Research (NIHR). The views expressed are those of the authors and not necessarily those of the NHS, the NIHR or the Department of Health The NIHR NHS Physical Environment Research Programme is funded by the Department of Health. 


\section{REFERENCES}

[1] Hignett, S. and Lu, J. Space to care and treat safely in acute hospitals: Recommendations from 1866-2008, Applied Ergonomics, (in press, doi. 10.1016/j.apergo.2009.12.010)

[2] Stanton, G., The Development of Ergonomics Data for Health Building Design Guidance, Ergonomics, 1983, 26(8), 375-393.

[3] Ljungberg, A.S., Kilborn, A. and Hägg, G., Occupational lifting by nursing aides and warehouse workers, Ergonomics, 1989, 32(1), 59-78.

[4] Rogers, R. and Salvage, J., Nurses at Risk: A Guide to Health and Safety at Work, Heinemann Nursing, Oxford, 1988, p 125.

[5] Chard, C., Health and Safety for Nurses, Chapman and Hall, London, 1993. p 167-180.

[6] Hignett, S. and Richardson, B., Manual handling human loads in a hospital: an exploratory study to identify nurses' perceptions, Applied Ergonomics, 1995, 26(3), 221-226.

[7] Garg, A. and Owen, B., Reducing back stress in nursing personnel: an ergonomic intervention in a nursing home, Ergonomics, 1992, 35(11), 1353-1375.

[8] Dyson, M., Modern critical care unit design, Nursing in Critical Care, 1996, 1(4), 194-201.

[9] Gurses, A.P. and Carayon, P., Exploring performance obstacles of intensive care nurses, Applied Ergonomics, 2009, 40, 509-518.

[10] Reiling, J.G., Knutzen, B.L., Wallen, T.K., et al., Enhancing the traditional hospital design process: a focus on patient safety. Joint Commission Journal of Quality and Safety, 2004, 30(3), 115-124.

[11] Sackett, D., Richardson, W.S., Rosenberg, W., et al. Evidence Based Medicine: How to teach and practice EBM, $1^{\text {st }}$ edn., Churchill Livingstone, Edinburgh. 1997.

[12] Hamilton, D.K. Design for Patient Units. http://www.muhc-healing.mcgill.ca/english/Speakers/ hamilton_p2.html, 2003, (accessed 23 October 2009).

[13] Swaim, T.J., Staff involvement in critical care construction, Critical Care Nursing Quarterly, 1991, 14(1), 63-70.

[14] Hardesty, T., Knowledge that nurses need to participate on a design team, Nursing Management, 1988, 19(3), 49-57.

[15] Harrell, J.W., User driven design process, Critical Care Nursing Quarterly, 1991, 14(1), 21-29.

[16] Munn, E.M. and Saulsbery, P.A.H., Facility Planning: A blueprint for Nurse Executives, Journal of Nursing Administration, 1992, 22(1), 13-17.

[17] Rutter, B.G., Designing the ergonomically correct medical environment, Journal of Healthcare Design, 1996, 8, 127-131.

[18] Gregory, M. Concepts in headwall selection and design, Critical Care Nursing Quarterly, 1993, 16(3), $51-55$.

[19] Vincent, D.R., Taslan, D.H. and Stromberg D., Beyond the mock-up: the value of temporary occupancy and evaluation, The Academy Journal, 2001, Sept. www.aia.org/static/journal/ ARTICLES/v4_04/article04asp Accessed 24th November 2005.

[20] Zilm, F., Four key decisions in the evolution of a critical care unit, Critical Care Nursing Quarterly, 1991, 14(1), 9-20.

[21] Haugh, R., The Patient Room: Administrative. Standardizing where things to in a room and other fairly simple ideas pay off, Hospitals and Health Networks, 2004, 78(5), 34-36.

[22] Patterson, C.B. and Abrahão, J.I., Real Space: the common dimension of Ergonomics and Architecture, Proceedings of the 17 th Triennial Congress of the International Ergonomics Association, Beijing, China, 9-14 August 2009.

[23] Watkins, N., Myers, D. and Villasante, R., Mock-ups as 'interactive laboratories': mixed methods research using inpatient unit room mock-ups, Health Environments Research and Design, 2008, 2(1), 66-81.

[24] Cherry, E. and Petronis, J. Architectural Programming, http://www.wbdg.org/design/ dd_archprogramming.php, 2009 (accessed 8th October 2009). 
[25] Jastremski, C.A. and Harvey M., Making change to improve the intensive care experience for patients and their families, New Horizons, 1998, 6, 99-109.

[26] Novaes, M.A.F.P., Aronovich, A., Ferraz, M.B. and Knobel, E., Stressors in ICU: patients' evaluation, Intensive Care Med, 1997, 23, 1282-1285.

[27] Fontaine, D.K., Briggs, L.P. and Pope-Smith, B., Designing Humanistic Critical Care Environments, Critical Care Nursing Quarterly, 2001, 24(3), 21-34.

[28] Hendrich, A.L., Fay, J. and Sorrells, A.K., Effects of Acuity-Adaptable Rooms on Flow of Patients and Delivery of Care, American Journal of Critical Care, 2004, 13(1), 35-45.

[29] Garvey, T., Allison, D.. Adaptable patient room takes top prize. http://www.ingenious.carleton.ca/ 2005-01/40pf.htm, 2004, Accessed 23 $3^{\text {rd }}$ October 2009.

[30] Runy, L.A., The Patient Room: Universal Rooms, Hospitals and Health Networks, 2004, 78(5), 36-40.

[31] White, R.D., The Physical Environment of the Neonatal Intensive Care Unit - Implications for Premature Newborns and their Care-givers, Business Briefing: US Pediatric Care, 2005, 13-14.

[32] Laing, I., Ducker, T., Leaf, A, et al.. Designing a Neonatal Unit: Report for the British Association of Perinatal Medicine, 2004. http://www.bapm.org/media/documents/publications/DesigningNNU_ May2004b.pdf, Accessed 23 ${ }^{\text {rd }}$ October 2009.

[33] Brown, P. and Taquino, L., Designing and Delivering Neonatal Care in Single Rooms. Journal of Perinatal \& Neonatal Nursing, 2001, 15(1), 68-83.

[34] Shepley, M.M., Harris, D.D. and White, R.. Open Bay and Single Family Room Neonatal Intensive Care Units, Environment and Behaviour, 2008, 40(2), 249-268.

[35] Department of Health, Health Building Note No. 21. Maternity Department, The Stationary Office, London, 1996.

[36] Hignett, S. and Lu, J., Improving the Design of Neonatal Cot Space, Department of Health Estates and Facilities Management Research Report B(05)02, The Stationary Office, London, (in press).

[37] Fray, M. and Hignett, S., Review and Validation of Neonatal Cot Space Recommendation, Department of Health Estates and Facilities Management Centre of Information report Reference: COI/5768 The Stationary Office, London, (in press).

[38] Hignett, S.,Waterson, P., Task Envelopes: The Missing Link? In Bust, P. (ed.) Contemporary Ergonomics. London: Taylor \& Francis 351-356. 2008.

[39] Hignett, S., Lu, J. and Morgan, K., Empirical review of NHS Estates Ergonomic Drawings, Department of Health Estates and Facilities Management Research Report B(02)13. The Stationary Office, London, 2008.

[40] Nuffield Provincial Hospitals Trust, Studies in the functions and design of hospitals, Oxford University Press, London, 1955.

[41] Hignett, S. and Keen, E., How much space is needed to operate a mobile and an overhead patient hoist? Professional Nurse, 2005, 20(7), 40-42.

[42] Hignett, S. and Evans, D., Spatial requirements for patient handling in hospital shower/toilet rooms, Nursing Standard, 2006, 21(3), 43-48.

[43] Kirwan, B. and Ainsworth, L.K., A Guide to Task Analysis, Taylor \& Francis, London, 1992.

[44] Shepherd, A., Hierarchical Task Analysis, Taylor and Francis, London, 2001, 8-24.

[45] The $7^{\text {th }}$ US Consensus Committee, Recommended Standards for Newborn ICU Design, 2007, http://www.nd.edu/ nicudes/, accessed $5^{\text {th }}$ February 2009.

[46] Mathur, N.S., A Single-room NICU - the Next Generation Evolution in the Design of Neonatal Intensive Care Units. 2004 http://www.aia.org/aah_a_jrnl_0401_article3\&grandCh=yes. Accessed $29^{\text {th }}$ December 2008.

[47] Harrell, M.F., Headwall considerations for critical care unit designs, Critical Care Nursing Quarterly, 1991, 14(1), 50-53. 
[48] Lee, S., Designing and developing a new high dependency unit, Nursing in Critical Care, 1996, 1(4), 198-201.

[49] Moore, S., Critical care unit design: a collaborative approach, Critical Care Nursing Quarterly, 1993, 16(3), 15-26.

[50] Pheasant, S., Body Space. Anthropometry, Ergonomics and the Design of Work. $2^{\text {nd }}$ Edn., Taylor \& Francis, London. 1996.

[51] Dept. of Health. HBN 09-02 Maternity Care Facilities. The Stationary Office, London. 2008.

[52] University Hospitals of Leicester. Annual Report 2008/09. http://www.uhl-tr.nhs.uk/aboutus/ourannual-reports (accessed 12 March 2010). p 30. 


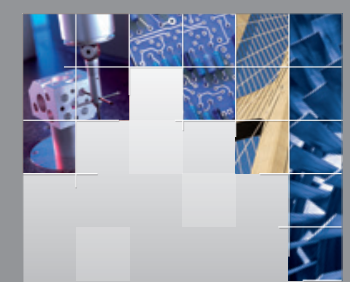

\section{Enfincering}
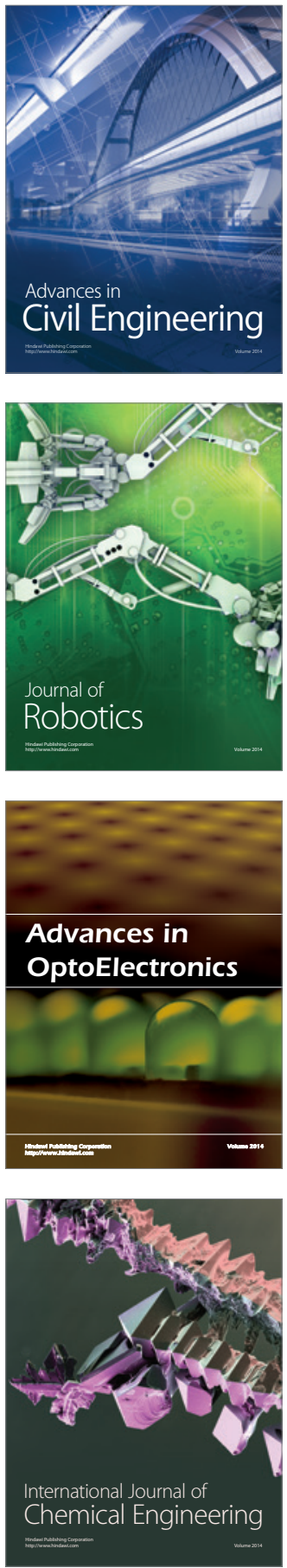

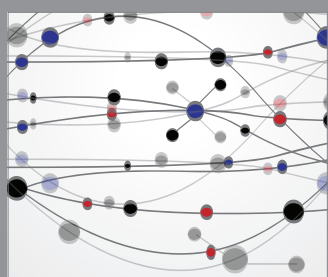

The Scientific World Journal

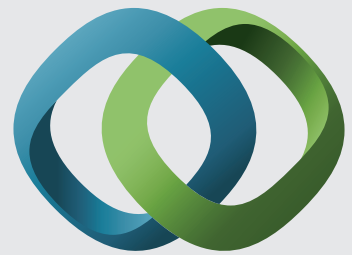

\section{Hindawi}

Submit your manuscripts at

http://www.hindawi.com
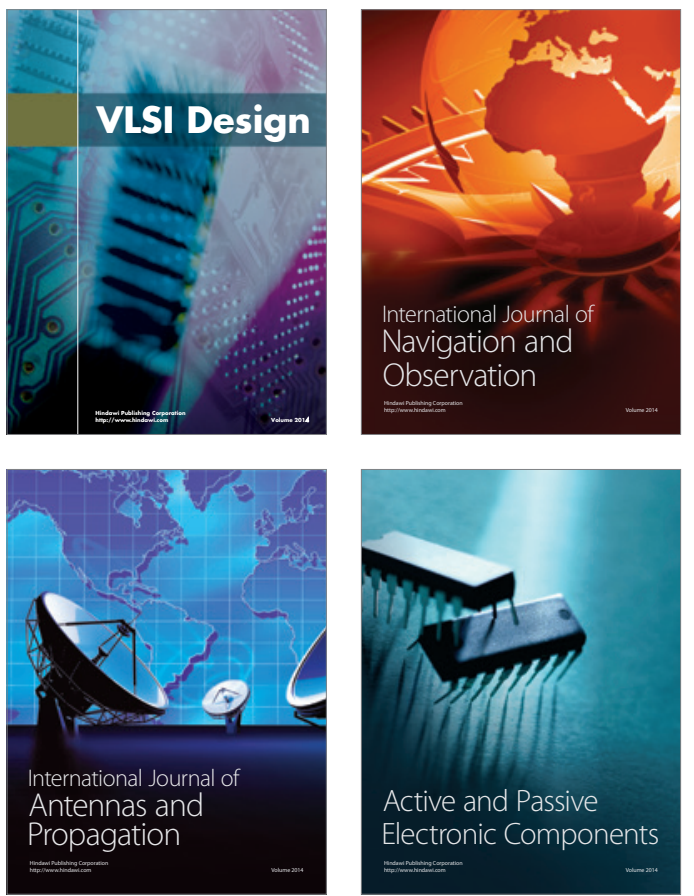
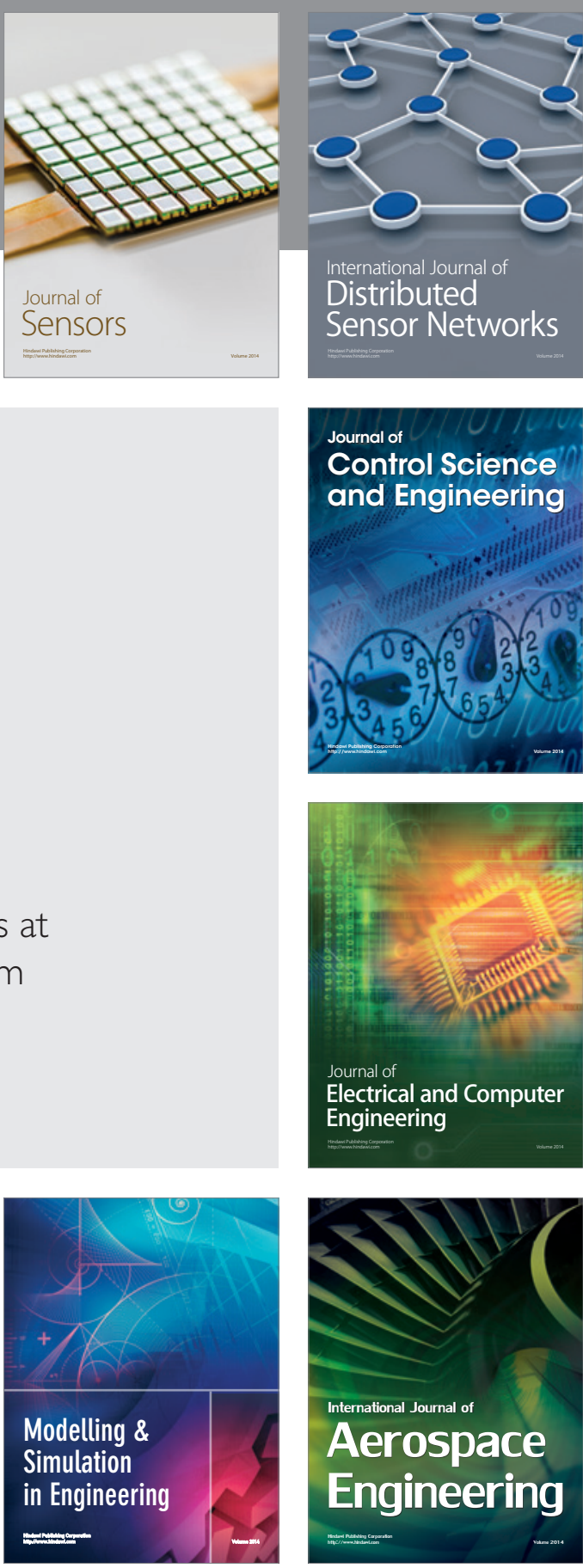

International Journal of

Distributed

Sensor Networks

Journal of

Control Science

and Engineering
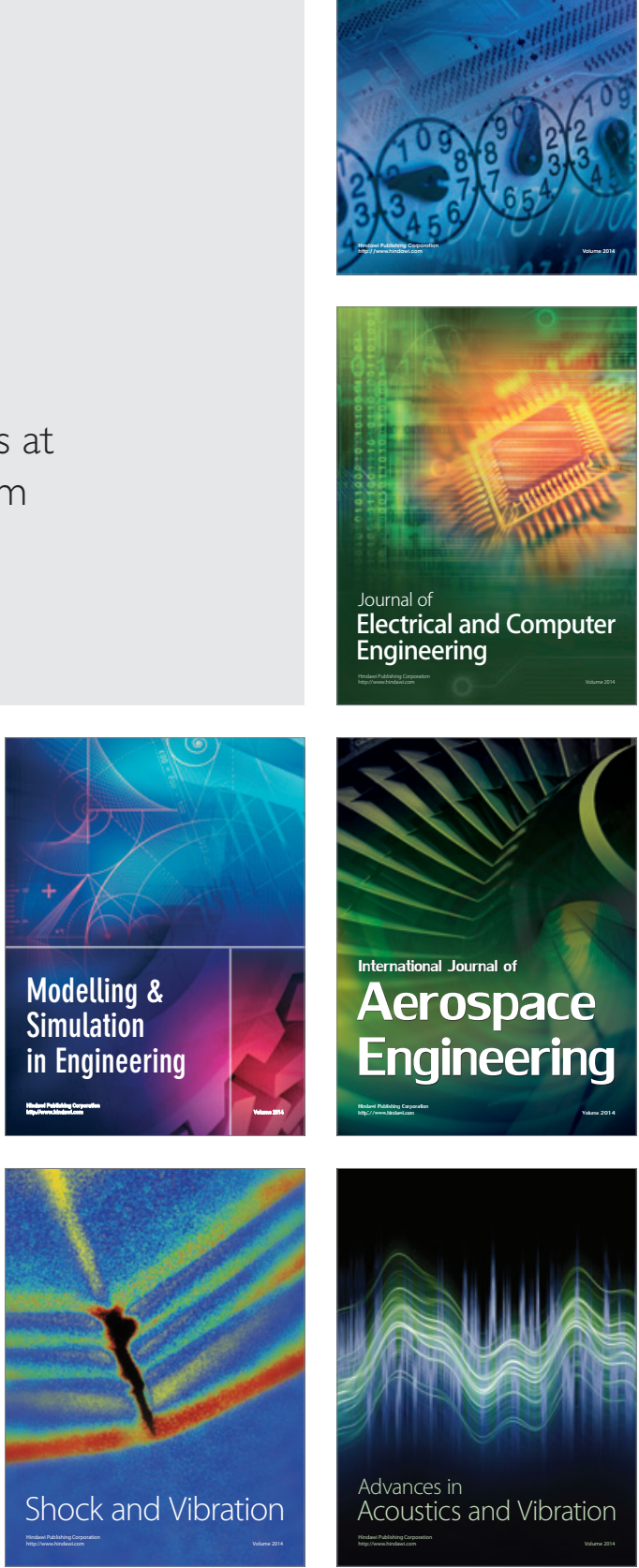